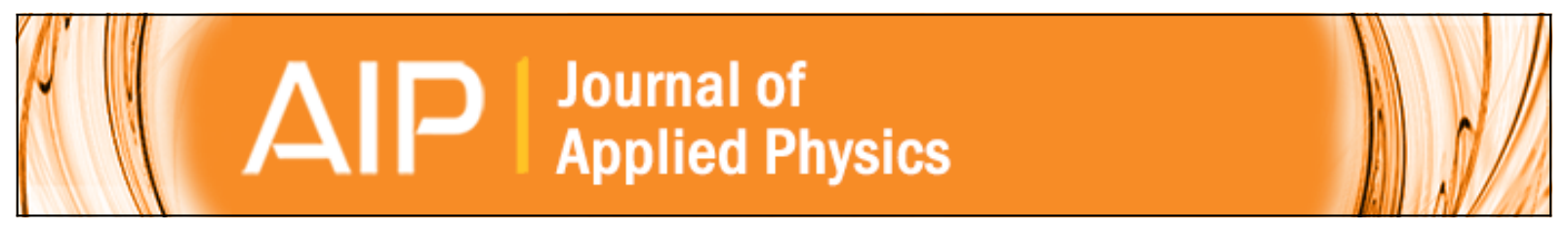

\title{
Influence of cap layer on implantation induced interdiffusion in InP/InGaAs quantum wells
}

C. Carmody, H. H. Tan, and C. Jagadish

Citation: Journal of Applied Physics 93, 4468 (2003); doi: 10.1063/1.1555273

View online: http://dx.doi.org/10.1063/1.1555273

View Table of Contents: http://scitation.aip.org/content/aip/journal/jap/93/8?ver=pdfcov

Published by the AIP Publishing

\section{Articles you may be interested in}

SiNx-induced intermixing in AllnGaAs/InP quantum well through interdiffusion of group III atoms

J. Appl. Phys. 112, 093109 (2012); 10.1063/1.4764856

Ion channeling effects on quantum well intermixing in phosphorus-implanted $\operatorname{lnGaAsP} / \operatorname{InGaAs} / \operatorname{InP}$ J. Appl. Phys. 98, 054904 (2005); 10.1063/1.2033143

Influence of nitride and oxide cap layers upon the annealing of $1.3 \mu \mathrm{m}$ GalnNAs/GaAs quantum wells J. Appl. Phys. 95, 4102 (2004); 10.1063/1.1687988

A comparison of spectroscopic and microscopic observations of ion-induced intermixing in InGaAs/lnP quantum wells

Appl. Phys. Lett. 72, 1599 (1998); 10.1063/1.121185

Oxygen implantation induced interdiffusion in $\mathrm{AlGaAs} / \mathrm{GaAs}$ quantum well structures

J. Vac. Sci. Technol. B 15, 845 (1997); 10.1116/1.589496

\section{AIP $\left.\right|_{\text {APL Photonics }}$}

APL Photonics is pleased to announce Benjamin Eggleton as its Editor-in-Chief

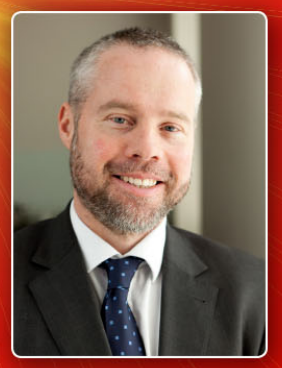




\title{
Influence of cap layer on implantation induced interdiffusion in InP/InGaAs quantum wells
}

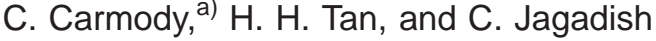 \\ Department of Electronic Materials Engineering, Research School of Physical Sciences and Engineering, \\ Australian National University, Canberra A C T 0200, Australia
}

(Received 4 November 2002; accepted 27 December 2002)

\begin{abstract}
We have investigated the effect of implantation at room temperature and $200{ }^{\circ} \mathrm{C}$ into lattice matched $\mathrm{InP} / \mathrm{InGaAs}$ quantum well structures capped with $\mathrm{InP}$ and InGaAs layers. $\mathrm{P}^{-}$ions of $20 \mathrm{keV}$ were implanted into the cap layer at doses of $1 \times 10^{12}-1 \times 10^{14} \mathrm{~cm}^{-2}$. The dose dependent evolution of shifts in photoluminescence energy for the InP capped sample was found to be affected by the implant temperature. Rutherford back scattering measurements show that the nature of the damage induced at different implant temperatures is responsible for this behavior. It was found that the InGaAs capped sample was less sensitive to the implant temperature than the InP capped sample.

(c) 2003 American Institute of Physics. [DOI: 10.1063/1.1555273]
\end{abstract}

\section{INTRODUCTION}

Quantum well interdiffusion technology has become increasingly important in the drive towards fabrication of photonic integrated circuits due to its versatile band gap tuning process, which does not have the disadvantages of the regrowth methods. Band gap tuning is achieved by the introduction of point defects into the quantum well active region, which allows atomic diffusion to take place between the quantum well and barrier materials. In this way, the quantum well profile, and consequently the corresponding energy eigenstates, are altered. Laser induced annealing, ${ }^{1}$ impurity free vacancy disordering, ${ }^{2,3}$ ion implantation induced interdiffusion, ${ }^{4,5}$ and impurity induced diffusion ${ }^{6}$ are examples of methods of band gap tuning that are currently being researched. From the point of view of optical fiber communications technology, which is the most important form of data transmission in the internet age, the lattice matched InGaAs/InP quantum well system has received a lot of interest. It is an ideal candidate for the fabrication of optoelectronic devices which are needed to operate at the 1.3 and $1.55 \mu \mathrm{m}$ wavelengths. While the effect of cap layer implantation in this system has been investigated in recent work, ${ }^{7-9}$ a comparison between different types of capping layers, and their impact on the degree of interdiffusion as a function of implant dose, has not been made. In this work, we study the effect of the cap layer and the implant temperature on shifts in photoluminescence energy in InGaAs/InP quantum wells. We have found that the temperature of the sample during implantation has an important effect on the evolution of the interdiffusion with the dose.

\section{EXPERIMENT}

Two wafers were grown by metalorganic chemical vapor deposition (MOCVD) on (100) semi-insulating InP substrates. Both wafers had a single $5 \mathrm{~nm} \mathrm{In}_{0.53} \mathrm{Ga}_{0.47} \mathrm{As}$ quantum well and InP barriers. The first sample had a $250 \mathrm{~nm} \mathrm{InP}$

\footnotetext{
${ }^{a)}$ Electronic mail: cyc109@rsphysse.anu.edu.au
}

cap layer, and the second had a $200 \mathrm{~nm} \mathrm{InP}$ barrier followed by a $50 \mathrm{~nm} \mathrm{In} 0.53 \mathrm{Ga}_{0.47} \mathrm{As}$ capping layer. The samples were implanted with $\mathrm{P}^{-}$ions at $20 \mathrm{keV}$, an energy identified by TRIM simulations as sufficient to place all the damage within the first $50 \mathrm{~nm}$ of the surface. The doses ranged between $1 \times 10^{12}$ and $1 \times 10^{14} \mathrm{~cm}^{-2}$, and all implants were performed with a constant flux of $7 \mathrm{nA} / \mathrm{cm}^{2}$ and the sample tilted $7^{\circ}$ from the normal direction of the beam to minimize channeling effects. In each case one half of the sample was masked in order to provide a reference. Rapid thermal annealing (RTA) at $700{ }^{\circ} \mathrm{C}$ for $60 \mathrm{~s}$ was conducted on all samples after implantation. This temperature was chosen after a study into the degree of thermal interdiffusion caused by annealing; a minimal change in peak emission compared to the unannealed value was observed at this temperature, therefore we were satisfied that any shifts we observed were a result of implantation induced damage in the cap layer. Photoluminescence (PL) at $77 \mathrm{~K}$ using a red diode laser at $670 \mathrm{~nm}$ and an InGaAs photodetector through a $0.5 \mathrm{~m}$ monochromator was used to measure the shifts in quantum well emission. The relative shifts in PL energy were calculated by the difference between the emission energy of the implanted side and that of the (annealed) reference side of the same sample. Rutherford backscattering spectrometry/channeling (RBS/C) using $2 \mathrm{MeV} \mathrm{He}^{+}$ions was also performed with $10^{\circ}$ glancing angle geometry.

\section{RESULTS AND DISCUSSION}

Figure 1 illustrates the blueshift of PL emission from the InP capped sample with an increase in ion dose when implanted with $\mathrm{P}^{-}$ions at room temperature and $200{ }^{\circ} \mathrm{C}$. As the dose is increased, the shift in emission from the sample implanted at $200{ }^{\circ} \mathrm{C}$ increases to $90 \mathrm{meV}$ at a dose of 1 $\times 10^{14} \mathrm{~cm}^{-2}$, while for room temperature implantation the shift in energy reaches a maximum of $40 \mathrm{meV}$ at a dose of $1 \times 10^{13} \mathrm{~cm}^{-2}$, and decreases beyond this dose. Figure $2 \mathrm{de}-$ picts the relative shifts of the InGaAs capped sample as a function of the dose for $20 \mathrm{keV} \mathrm{P}^{-}$ions and also implanted 


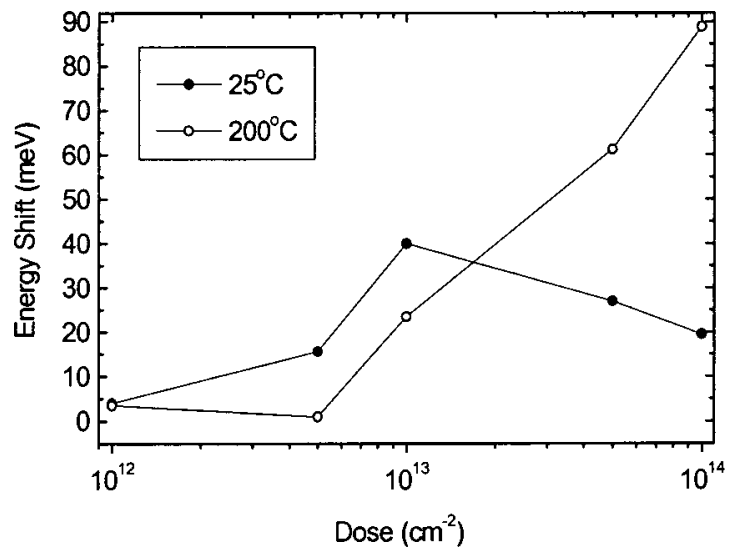

FIG. 1. Shift in PL energy as a function of the $20 \mathrm{keV} \mathrm{P^{- }}$ ion dose (annealed at $700{ }^{\circ} \mathrm{C}$ for $60 \mathrm{~s}$ ) for an InP capped sample at two implantation temperatures. Carmody et al.

at room temperature and $200{ }^{\circ} \mathrm{C}$. In this case the shift in energy increases with the dose for both implantation temperatures. We note that the shifts are marginally greater for implantation at room temperature than at $200{ }^{\circ} \mathrm{C}$.

Figures 1 and 2 illustrate that the level of interdiffusion at a particular dose is greatly modified by the type of capping layer. Additionally, the temperature of implantation produces different evolution of the shifts according to the dose.

In order to understand these differences in energy shift, residual damage after ion implantation was measured using RBS/C. Figure 3 shows the glancing angle RBS-C spectra measured for the InP capped sample implanted at room temperature to a dose of $1 \times 10^{14} \mathrm{~cm}^{-2}$. The region near the surface is nearly amorphized at this implant temperature. A similar measurement for implantation at $200{ }^{\circ} \mathrm{C}$ shows negligible variation from that of the unimplanted spectrum. Dynamic annealing is an important characteristic of implanted InP: at room temperature it is known that over a period of many days damaged material will begin to recrystallize. ${ }^{10} \mathrm{It}$ follows that for implantation at $200{ }^{\circ} \mathrm{C}$ dynamic annealing is significant. At this temperature, amorphization is suppressed and more point defects are generated, which will lead to

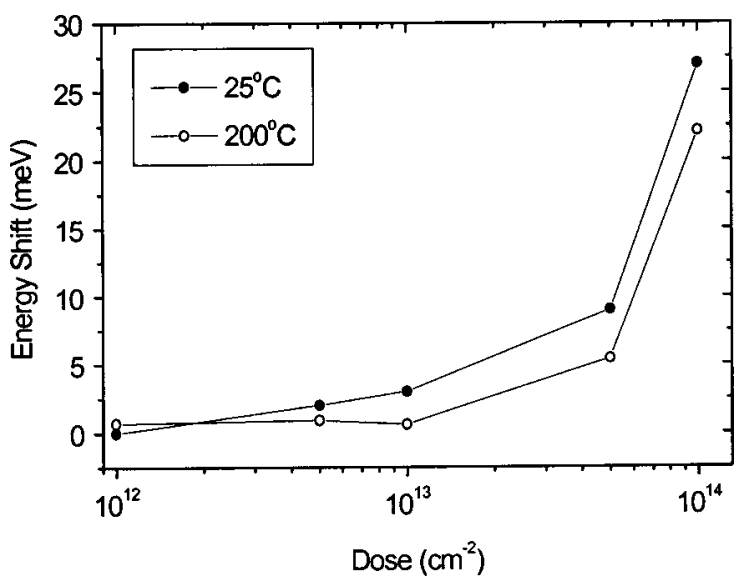

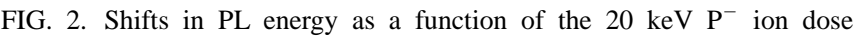
(annealed at $700{ }^{\circ} \mathrm{C}$ for $60 \mathrm{~s}$ ) for the InGaAs capped sample at two implantation temperatures. Carmody et al.

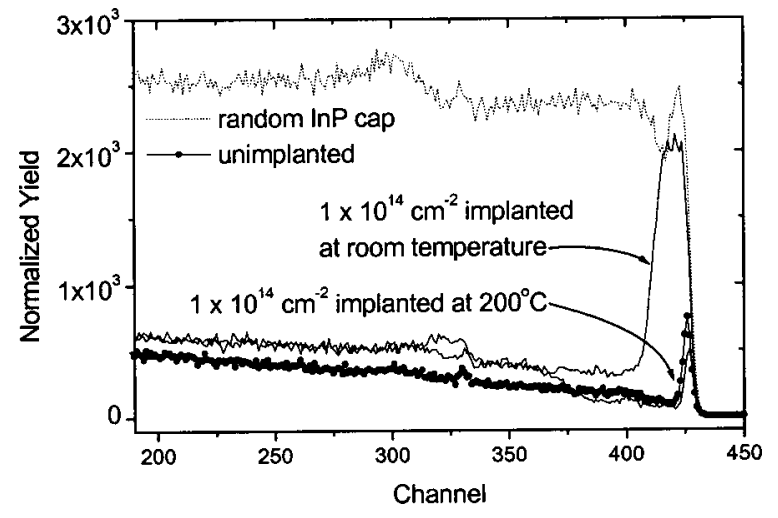

FIG. 3. Glancing angle Rutherford backscattering spectra of the InP capped sample implanted with $20 \mathrm{keV} \mathrm{P} \mathrm{P}^{-}$to a dose of $1 \times 10^{14} \mathrm{~cm}^{-2}$ at room temperature. Carmody et al.

enhanced interdiffusion during rapid thermal annealing. By contrast, for room temperature implantation of the InP capped sample, defect clusters in the amorphized region have higher thermal stability and thus contribute less to intermixing. InP capped samples irradiated at a dose of 1 $\times 10^{13} \mathrm{~cm}^{-2}$ were also measured (not shown) for both implant temperatures, and again they show very little difference from the unimplanted spectrum. This lack of significant damage at lower doses correlates well with the large shifts observed. It is likely that, at this dose of $1 \times 10^{13} \mathrm{~cm}^{-2}$, the shift in energy is slightly reduced for $200{ }^{\circ} \mathrm{C}$ implantation, because at this temperature there are fewer point defects due to dynamic annealing. The RBS/C spectra for the InGaAs capped samples are shown in Fig. 4. All samples for doses of $1 \times 10^{13}$ and $1 \times 10^{14} \mathrm{~cm}^{-2}$ and for both room temperature and $200{ }^{\circ} \mathrm{C}$ implantation showed evidence of only a small amount of damage; there was no amorphization. There is a very slight increase in the amount of damage for implantation at higher dose, but almost no difference between the two implantation temperatures. We cannot distinguish between the type of damage induced at the different implant temperatures from the RBS/C measurements, however we suggest that the decreased shifts in energy observed for $200{ }^{\circ} \mathrm{C}$ implantation into the InGaAs capped samples are due to a lower concentration of point defects. The number of point

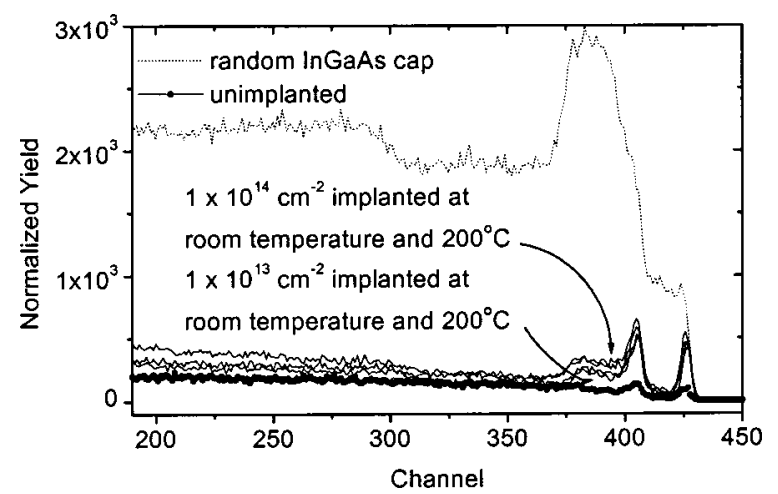

FIG. 4. Glancing angle Rutherford backscattering spectra of the InGaAs capped sample implanted with $20 \mathrm{keV} \mathrm{P^{- }}$ to a dose of $1 \times 10^{14} \mathrm{~cm}^{-2}$ at room temperature. Carmody et al. 
defects will be reduced by a greater amount of dynamic annealing and/or the formation of clusters, and it is likely that such processes occur more readily at elevated implantation temperatures (as for InP).

It is obvious from the RBS/C measurements that the defect accumulation and diffusion mechanisms are different for the InP and InGaAs cap layers. The nature of the defects is specific to the layer, as can be inferred from the unique temperature dependence of the dynamic annealing in either InP or InGaAs. The In-P bond strength was measured as $\sim 198 \mathrm{~kJ} \mathrm{~mol}^{-1}$, whereas the $\mathrm{In}-\mathrm{As}$ and $\mathrm{Ga}-\mathrm{As}$ bond strengths are $\sim 201$ and $\sim 210 \mathrm{~kJ} \mathrm{~mol}^{-1}$, respectively. ${ }^{11}$ Thus, the bonds in InP are much easier to break, and room temperature implantation into $\mathrm{InP}$ causes much more damage than implantation into InGaAs at the same temperature. For example, the room temperature amorphization doses for $\mathrm{Se}^{+}$ implantation into InP, InAs, and GaAs were measured to be $1.8 \times 10^{13}, 7 \times 10^{13}$, and $32 \times 10^{13} \mathrm{~cm}^{-2}$, respectively. ${ }^{12}$ The indium and phosphorus self-diffusion factors, $D_{0}$, in InP are $1 \times 10^{5}$ and $7 \times 10^{10} \mathrm{~cm}^{2} / \mathrm{s}$, respectively. ${ }^{11}$ For In selfdiffusion in InAs, $D_{0}$ is $6 \times 10^{5} \mathrm{~cm}^{2} / \mathrm{s}$, for As self-diffusion in InAs it is $3 \times 10^{7} \mathrm{~cm}^{2} / \mathrm{s}$, for As diffusion in $\mathrm{GaAs}$ it is 7 $\times 10^{-1} \mathrm{~cm}^{2} / \mathrm{s}$, and for Ga self-diffusion in GaAs it is 1 $\times 10^{7} \mathrm{~cm}^{2} / \mathrm{s}$ (values for InGaAs could not be obtained). We note that the greatest shifts in photoluminescence energy obtained were for implantation at $200{ }^{\circ} \mathrm{C}$ into the InP capped sample. From the diffusion factors listed above, we suggest that phosphorus-related point defects created in InP by implantation at $200{ }^{\circ} \mathrm{C}$ will be very mobile and, by comparison, the degree of diffusion of any of the point defects created in InGaAs will be orders of magnitude less. It is possible that greater shifts are achievable in the InGaAs capped samples if implantation is done at higher doses.

\section{CONCLUSION}

Shallow ion implantation was used to study the effect of the cap layer and implantation temperature in an InP/InGaAs quantum well system. The greatest shifts occur for the InP capped sample where amorphization is suppressed at elevated temperature implantation. In the case of InGaAs capped samples, room temperature implantation shows a marginally higher energy shift than that at $200{ }^{\circ} \mathrm{C}$, possibly due to the greater quantity of point defects created at the lower temperature.

${ }^{1}$ D. K. Sengupta, T. Horton, W. Fang, A. Curtis, J. Li, S. L. Chuang, H. Chen, M. Feng, and G. E. Stillman, Appl. Phys. Lett. 70, 3573 (1997).

${ }^{2}$ D. Sengupta et al., IEEE J. Sel. Top. Quantum Electron. 4, 746 (1998).

${ }^{3}$ G. Li, S. J. Chua, S. J. Xu, X. C. Wang, A. Saher Helmy, M.-L. Ke, and J. H. Marsh, Appl. Phys. Lett. 73, 3393 (1998).

${ }^{4}$ H. Sumida, H. Asahi, S. J. Yu, K. Asami, S.-i. Gonda, and H. Tanoue, Appl. Phys. Lett. 54, 520 (1989).

${ }^{5}$ H. Chen et al., J. Appl. Phys. 89, 4815 (2001).

${ }^{6}$ D. G. Deppe, N. Holonyak, Jr., W. E. Plano, V. M. Robbins, J. M. Dallesasse, K. C. Hsieh, and J. E. Baker, J. Appl. Phys. 64, 1838 (1988).

${ }^{7}$ R. D. Goldberg et al., Mater. Res. Soc. Symp. Proc. 540, 15 (1998).

${ }^{8}$ H. Chen, R. M. Feenstra, P. G. Piva, R. D. Goldberg, I. V. Mitchell, G. C. Aers, P. J. Poole, and S. Charbonneau., Appl. Phys. Lett. 75, 79 (1999).

${ }^{9}$ M. Paquette J. Beauvais, J. Beerens, P. J. Poole, S. Charbonneau, C. J. Miner, and C. Blaauw, Appl. Phys. Lett. 71, 3749 (1997).

${ }^{10}$ U. G. Akano, I. V. Mitchell, F. R. Shepherd, and C. J. Miner, J. Vac. Sci. Technol. A 10, 996 (1992).

${ }^{11}$ CRC Handbook of Chemistry and Physics, edited by D. R. Lide (Chemical Rubber, Boca Raton, FL, 9.129,12.88 1992), pp. 9.129-12.88.

${ }^{12}$ W. Wesch, E. Wendler, G. Götz, and N. P. Kekelidse, J. Appl. Phys. 65, 519 (1989). 